\title{
Structural and Microstructural Correlations of Physical Properties in Natural Almandine-Pyrope Solid Solution: $\mathrm{Al}_{70} \mathrm{Py}_{29}$
}

\author{
N. SIBI $^{1}$ and G. SUBODH ${ }^{1,2}$ \\ 1.-Department of Physics, University of Kerala, Thiruvananthapuram, Kerala 695581, India. \\ 2.-e-mail: gsubodh@gmail.com
}

\begin{abstract}
Garnets are naturally occurring minerals with the general formula $\mathrm{X}_{3} \mathrm{Y}_{2} \mathrm{Z}_{3} \mathrm{O}_{12}$ having various applications. In the present study, the structural and physical properties of a garnet mineral obtained from Indian Rare Earth Ltd., Manavalakurichi, Tamil Nadu, India were comprehensively investigated. The compositional analysis using electron probe micro analysis (EPMA) revealed that the mineral belongs to almandine-pyrope solid solution $\left(\mathrm{Al}_{70} \mathrm{Py}_{29}\right)$ with the chemical formula $\left(\mathrm{Fe}_{1.72} \mathrm{Mg}_{0.8} \mathrm{Mn}_{0.01} \mathrm{Ca}_{0.02}\right)\left(\mathrm{Fe}_{0.04} \mathrm{Al}_{2.36}\right) \mathrm{Si}_{2.93} \mathrm{O}_{12}$. Rietveld refinement of the x-ray diffraction pattern confirms that the space group is $I a-\overline{3} d$ with refined cubic lattice parameter $a=11.550(4) \AA$. The refined occupancy values of multiple cations in the dodecahedral and octahedral sites are in agreement with the EPMA data. Fourier transform infrared and FT Raman spectra show bands corresponding to almandine-pyrope solid solution. Peak splitting of IR and Raman bands confirms presence of multiple cations in the dodecahedral site. Thermogravimetric/differential thermal analysis shows that the mineral is stable up to $600^{\circ} \mathrm{C}$ in spite of the presence of $\mathrm{Fe}^{2+}$ ions. Low temperature magnetic susceptibility data is in agreement with the amount of $\mathrm{Fe}^{2+}$ ions present in the mineral. The dielectric constant of the mineral varied from 6 to 16.5 when sintered at temperatures ranging from $600^{\circ} \mathrm{C}$ to $1250^{\circ} \mathrm{C}$.
\end{abstract}

Key words: Garnet, almandine-pyrope solid solution, microstructure, vibrational spectra, dielectric and magnetic properties

\section{INTRODUCTION}

Garnets are a class of minerals found in earth's crust, upper mantle and transition zone. They are extensively used as gemstones. Materials with garnet structure have wide range of applications such as in computer memories, lasers, microwave optical elements, magnetic technologies, ion conducting technologies, white light emitting diodes (LED), abrasives, water jet cutting, etc. ${ }^{1,2}$ Garnets have the general chemical formula of ${ }^{\mathrm{VIII}}\left\{\mathrm{X}_{3}\right]^{\mathrm{VI}}\left[\mathrm{Y}_{2}\right]$ ${ }^{I V}\left(Z_{3}\right) O_{12}$, where $\{X\}$ is a dodecahedral site occupied by a divalent cation ( $\mathrm{Fe}, \mathrm{Mg}, \mathrm{Mn}, \mathrm{Ca}$, etc.) in the $24 \mathrm{c}$ position of $222\left(\mathrm{D}_{2}\right)$ point symmetry, $Y$ is an octahedral site occupied by a trivalent cation $(\mathrm{Al}$, $\mathrm{Fe}$, etc.) in the $16 a$ position of $\overline{3},\left(\mathrm{~S}_{6}\right)$ point symmetry

(Received May 4, 2017; accepted September 8, 2017; published online September 23, 2017) and $(\mathrm{Z})$ is a tetrahedral site occupied by tetravalent cations $\left(\mathrm{V}, \mathrm{Ti}\right.$, etc.) in the $24 d$ position of $\overline{4}\left(\mathrm{~S}_{4}\right)$ point symmetry. ${ }^{3}$ Figure $\mathrm{S} 1$ shows the crystal structure of garnet. The superscripts indicate the co-ordination number of each cation. Garnets have a cubic structure with space group $I a-\overline{3} d$ with eight molecules per unit cell. Their lattice parameters range between $a=11.5-12.0 \AA$ and densities between $3.5 \mathrm{~g} / \mathrm{cm}^{3}$ and $4.3 \mathrm{~g} / \mathrm{cm}^{3}$ They are classified into two major groups; Pyralspites and Ugrandites. Almandine $\left(\mathrm{Fe}_{3} \mathrm{Al}_{2} \mathrm{Si}_{3} \mathrm{O}_{12}\right)$, Pyrope $\left(\mathrm{Mg}_{3} \mathrm{Al}_{2} \mathrm{Si}_{3} \mathrm{O}_{12}\right)$ and Spessartine $\left(\mathrm{Mn}_{3} \mathrm{Al}_{2} \mathrm{Si}_{3} \mathrm{O}_{12}\right)$ are the members of Pyralspites. ${ }^{1}$ The Ugrandites are a class comprised of Uvarovite $\left[\mathrm{Ca}_{3} \mathrm{Cr}_{2} \mathrm{Si}_{3} \mathrm{O}_{12}\right]$, Grossular $\left[\mathrm{Ca}_{3} \mathrm{Al}_{2}\right.$ $\left.\mathrm{Si}_{3} \mathrm{O}_{12}\right]$ and Andradite $\left[\mathrm{Ca}_{3} \mathrm{Fe}_{2} \mathrm{Si}_{3} \mathrm{O}_{12}\right]$. Mostly garnets exist as solid solutions of these endmembers. ${ }^{4,5} \mathrm{Fe}_{3-\mathrm{x}} \mathrm{Mg}_{\mathrm{x}} \mathrm{Al}_{2} \mathrm{Si}_{3} \mathrm{O}_{12}$ is an end member of the almandine-pyrope solid solution binary. Fe and $\mathrm{Mg}$ simultaneously occupy the dodecahedral 
site with the iron to magnesium atomic ratio varying randomly.

Garnets from different parts of the world have been studied by various authors for their geological peculiarities. Thermal analysis of some members of garnets from almandine-pyrope series at $1200^{\circ} \mathrm{C}$ have been reported by Zboril et al. ${ }^{2}$ The magnetic properties of some natural pyrope-almandine garnets were investigated by Oliveira et al. ${ }^{6}$ Raman and infrared spectroscopic analysis of synthetic garnets have been reported by various authors. ${ }^{3,7-9}$ The influence of cationic substitution in the dodecahedral site of almandine-pyrope solid solution in the IR and Raman spectrum was studied by Tarte et al., ${ }^{10}$ Ferrari et al. ${ }^{11}$ and Hofmeister et al. ${ }^{7}$ Mossbauer spectroscopic studies of garnets with $\mathrm{Fe}$ have been reported by a number of authors. ${ }^{2,6}$ Although, the geological peculiarities of garnets found in India have been extensively reported, investigations on structural and physical properties of garnets in almandine-pyrope series are limited. ${ }^{12-16}$

Materials with low dielectric constant $\left(\varepsilon_{\mathrm{r}}\right)$ and low dielectric loss $(\tan \delta$ ) are extremely demanding for microwave substrate applications. They facilitate fast signal propagation and hence, have wide range of applications in high speed communication devices. ${ }^{17} \mathrm{~A}$ few studies have been reported in which natural minerals have been investigated for their possible applications as microwave dielectric substrates. Recently, Jobin et al. ${ }^{18}$ reported microwave dielectric properties of zirconium silicate mineral-filled HDPE composites for microwave applications. ${ }^{19,20}$ Further, natural silica filled epoxy composites for electronic packaging applications were investigated by Teh et al. ${ }^{21}$ There were no reports on any types of garnet mineral for their use in electronic applications. For the complete understanding of physical properties, a comprehensive structural analysis is required. Hence, in this study, we present a detailed investigation on the crystal structure and microstructure of almandine-pyrope solid solution obtained from Indian Rare Earth Ltd. It is then correlated with the magnetic and dielectric properties of the mineral. The present study also aims to develop a natural garnet as a cost effective "green" dielectric material so as to check its feasibility as a suitable candidate for microwave applications.

\section{EXPERIMENTAL PROCEDURE}

The natural MK grade garnet mineral (Fig. S2) used in this study was supplied by Indian Rare Earth Ltd. Manavalakurichi. The chemical composition of micron sized grains of the sample was identified using electron probe micro-analysis (EPMA). The analysis was carried out using a JEOL JXA-8230 microprobe, with five spectrometers, at the AFMM, IISC Bangalore operating with an accelerating voltage of $15 \mathrm{kV}$, and a beam current of $12 \mathrm{nA}$. Perfectly polished surfaces of the garnet grains were mounted perpendicularly to the electron beam. Natural and synthetic silicates and oxides were used for calibration (Natural and Synthetic Mineral Standards provided by JEOL). The data were reduced using ZAF correction procedures. The mineral was ground in a ball miller using Ceria stabilised Zirconia balls in the distilled water medium for $72 \mathrm{~h}$. The ground powder (Fig. S3) was dried in a hot furnace at $200^{\circ} \mathrm{C}$ for $4 \mathrm{~h}$ and ground further in an agate mortar. The trace elements were identified using energy dispersive x-ray fluorescence spectroscopy, XRF (PANalytical-Epsilon 3, Netherlands using Omnian software). The crystal structure and phase purity of the mineral were analyzed using a BRUKER D8 advance $\mathrm{x}$ ray diffractometer (XRD), Germany with $\mathrm{CuK} \alpha$ radiation, $\lambda=1.5406 \AA$. Rietveld refinement was done using Topas 4.2 software. Thermal stability of the mineral was studied from Thermogravimetric/Differential Thermal Analysis (TGA/DTA) of the sample in a temperature range of $50-960^{\circ} \mathrm{C}$, in an oxygen atmosphere (Perkin Elmer STA 6000, Netherlands). Microstructural analysis was done using Scanning Electron Microscopy (FESEM, FEI: Nova Nano SEM 450, EDS Detector: Bruker, XFlash 6/10). Molecular spectroscopic analysis using infrared spectroscopy (Schimadzu IR affinity-1 FTIR spectrometer specially equipped with DR8 8000 reflectance accessory) was done after mixing the samples with KBr. Raman spectroscopic measurements were carried out with an excitation wavelength of $1064 \mathrm{~nm}$ (Bruker RFS 100 spectrophotometer, Nd: YAG laser source). Magnetic susceptibility was measured using a Superconducting Quantum Interference Device (SQUID) (MPMS, Quantum Design, UK). The sample was pressed into pellets and was heated at different temperatures for dielectric measurements. The radio frequency dielectric measurements were done using an LCR meter, (HIOKI IM 3536 LCR HI-TESTER, Japan). Pellets with a thickness of about $1-1.5 \mathrm{~mm}$ were used for measurement. A thick copper film with the same diameter of the pellet is fixed on both the surfaces as electrodes. Measures were taken so that there was no air gap between the copper film and pellet.

\section{RESULTS AND DISCUSSION}

\section{Chemical Composition of Garnet}

\section{Electron Probe Micro Analysis (EPMA)}

Determination of the chemical formula of the mineral was carried out using electron probe microanalysis (EPMA). It is a non-destructive technique for micron sized samples and is used for accurate, quantitative and qualitative determination of chemical composition of minerals. The EPMA analysis was done in wavelength-dispersive mode (WDS) and it is a spot analytic technique with spot sizes 
ranging between 0.1 and 2 microns. It has a detection limit of $0.1-0.01 \% .^{22}$ The weight percentage of oxides of various elements detected from EPMA and mol.\% of different garnets in the solid solution are given in Table I and the corresponding cationic calculations are shown in Table SI. The analysis was carried out for six grains. The amount of $\mathrm{Fe}^{3+}$ was found using methods for calculating the chemical formulae of minerals by considering stoichiometry and charge balance. ${ }^{23}$ The obtained chemical formula is:

$$
\left(\mathrm{Fe}_{1.72} \mathrm{Mg}_{0.8} \mathrm{Mn}_{0.01} \mathrm{Ca}_{0.02}\right)\left(\mathrm{Fe}_{0.04} \mathrm{Al}_{2.36}\right) \mathrm{Si}_{2.93} \mathrm{O}_{12} \text {. }
$$

The electron microprobe results gives the proportion of various types of garnets present in the mineral, and it is deduced to be $70.05 \mathrm{~mol} \%$ of almandine and $28.56 \mathrm{~mol} \%$ of pyrope. Hence, the present mineral can be labeled as $\mathrm{Al}_{70} \mathrm{Py}_{29}$. Other garnets present are below $2 \mathrm{~mol} \%$ and can be considered as impurities. Hence, it is confirmed that the garnet mineral obtained from Indian Rare Earth Limited belongs to the almandine-pyrope solid solution series with a trace amount of $\mathrm{Ca}$ and $\mathrm{Mn}$ possibly in the dodecahedral site. Also, the amount of $\mathrm{Fe}^{3+}$ ions is very low, and in the present mineral the iron exists almost in a single oxidation state; $\mathrm{Fe}^{2+}$.

\section{X-Ray Fluorescence Spectroscopy (XRF)}

Naturally occurring minerals may contain many trace elements, further ceria stabilized zirconia balls were used for milling garnet mineral. The abrasive nature of garnet mineral might produce ceria and zirconia as a result of milling for about $72 \mathrm{~h}$. In order to verify presence of trace elements, x-ray fluorescence spectroscopy (XRF) was used. Table SII shows the amount of trace elements obtained from XRF data. It shows the presence of zirconia and ceria in the powdered sample as a result of wearing of ceria stabilized zirconia balls used for milling garnet mineral. The presence of trace elements such as $\mathrm{TiO}_{2}, \mathrm{CdO}, \mathrm{HfO}_{2}, \mathrm{IrO}_{2}, \mathrm{Rb}_{2} \mathrm{O}$ and $\mathrm{Cr}_{2} \mathrm{O}_{3}$ were also detected. Minute amounts of some other rare earth elements were identified such as $\mathrm{Nd}_{2} \mathrm{O}_{3}$ and $\mathrm{Y}_{2} \mathrm{O}_{3}$.

\section{Crystal Structure of $\mathbf{A l}_{\mathbf{7 0}} \mathbf{P y}_{29}$}

The crystal structure of the mineral was investigated using the x-ray diffraction method. The powder diffraction pattern shows cubic symmetry for the mineral. Rietveld refinement of the XRD pattern was done using Topas 4.2 software. The refined XRD pattern is shown in Fig. 1. Rietveld refinement was done using the space group $I a-\overline{3} d$ (ICSD \#50619) and the obtained refinement parameters are $R_{\mathrm{wp}}=1.28 \%, R_{\exp }=1.03 \%$ and $\chi^{2}=1.25$. The refined atomic positions, occupancy and displacement parameters are shown in Table II. The lattice parameter obtained after Rietveld refinement is 11.550 (4) $\AA$, and there are eight formula units per unit cell. The theoretical density calculated from XRD is $3.94 \mathrm{~g} / \mathrm{cm}^{3}$.

The XRD data is consistent with the results obtained from EPMA analysis. It was confirmed that the garnet under study belongs to the almandine-pyrope series, with chemical formula $\left(\mathrm{Fe}_{1.72} \mathrm{Mg}_{0.8} \mathrm{Mn}_{0.01} \mathrm{Ca}_{0.02}\right)$ $\left(\mathrm{Fe}_{0.04} \mathrm{Al}_{2.36}\right) \mathrm{Si}_{2.93} \mathrm{O}_{12}$. The crystal structure obtained after refinement is shown in Fig. 2. Fe, $\mathrm{Mg}, \mathrm{Mn}$ and $\mathrm{Ca}$ are simultaneously occupying the dodecahedral site, even though there is a significant difference in the ionic radii and mass of $\mathrm{Ca}(1.12 \AA)$ and $\mathrm{Mg}(0.89 \AA)$ compared to that of $\mathrm{Fe}^{2+}(0.92 \AA)$ and $\mathrm{Mn}(0.96 \AA)$.

\section{Vibrational Spectra of $\mathbf{A l}_{\mathbf{7 0}} \mathbf{P y}_{29}$}

Vibrational spectroscopic analysis was carried out to confirm the multiple occupancy of cations at dodecahedral and octahedral sites. Theoretical factor group analysis on garnet has been reported by Koningstein et al. ${ }^{24}$ and Moore et al. ${ }^{25}$ The

Table I. Micro chemical analysis (expressed as wt.\% of oxides) and mol.\% of different types of garnets in the solid solution

\begin{tabular}{|c|c|c|c|c|c|c|}
\hline & 1 & 2 & 3 & 4 & 5 & 6 \\
\hline \multicolumn{7}{|l|}{ Wt. \% of oxides } \\
\hline $\mathrm{SiO}_{2}$ & 38.010 & 38.263 & 38.162 & 38.810 & 38.360 & 38.050 \\
\hline $\mathrm{Al}_{2} \mathrm{O}_{3}$ & 30.370 & 30.226 & 30.153 & 22.750 & 22.110 & 21.870 \\
\hline $\mathrm{FeO}$ & 21.930 & 21.726 & 21.856 & 32.020 & 32.090 & 32.840 \\
\hline $\mathrm{MnO}$ & 0.160 & 0.079 & 0.093 & 0.320 & 0.310 & 0.330 \\
\hline $\mathrm{MgO}$ & 8.160 & 8.254 & 8.389 & 6.090 & 6.070 & 5.770 \\
\hline $\mathrm{CaO}$ & 0.610 & 0.583 & 0.595 & 0.010 & 0.050 & 0.010 \\
\hline $\begin{array}{l}\text { Total } \\
\text { mol.\% of garnets }\end{array}$ & 99.240 & 99.131 & 99.248 & 100.000 & 98.990 & 98.870 \\
\hline Almandine & 66.0 & 66.1 & 65.5 & 74.0 & 73.7 & 75.0 \\
\hline Spessartine & 0.4 & 0.2 & 0.2 & 0.8 & 0.7 & 0.8 \\
\hline Pyrope & 31.9 & 32.1 & 32.7 & 25.2 & 25.4 & 24.1 \\
\hline Grossular & 0 & 0 & 0 & 0 & 0 & 0 \\
\hline Andradite & 1.9 & 1.8 & 1.8 & 0 & 0.1 & 0 \\
\hline Total & 100.2 & 100.2 & 100.2 & 100 & 99.9 & 99.9 \\
\hline
\end{tabular}


irreducible representation of the garnet structure at the $\Gamma$ point is given by:

$$
\begin{aligned}
\Gamma= & 3 \mathrm{~A}_{1 \mathrm{~g}}+5 \mathrm{~A}_{2 \mathrm{~g}}+8 \mathrm{E}_{\mathrm{g}}+14 \mathrm{~F}_{1 \mathrm{~g}}+14 \mathrm{~F}_{2 \mathrm{~g}}+5 \mathrm{~A}_{1 \mathrm{u}} \\
& +5 \mathrm{~A}_{2 \mathrm{u}}+10 \mathrm{E}_{\mathrm{u}}+17 \mathrm{~F}_{1 \mathrm{u}}+16 \mathrm{~F}_{2 \mathrm{u}} .
\end{aligned}
$$

The factor group analysis shows that for garnets there are 17 infrared-active modes and 25 Raman active modes. ${ }^{22}$ The Raman active modes belong to $\mathrm{A}_{1 \mathrm{~g}}, \mathrm{E}_{\mathrm{g}}$ and $\mathrm{F}_{2 \mathrm{~g}}$ symmetries. IR active modes have the symmetry, $\mathrm{F}_{1 \mathrm{u}}{ }^{3}$ It has been reported that the presence of different cations in the dodecahedral site will lower the symmetry of many garnet solid solutions like almandine-grossular, pyrope-grossular, etc. ${ }^{7}$ However, for almandine-pyrope solid solution, no lowering of symmetry has been reported due to multiple cations in the dodecahedral site, and the space group remains as $I a-\overline{3} d$.

In the present almandine-pyrope solid solution, a large difference in ionic radii and mass of $\mathrm{Ca} \& \mathrm{Mg}$ in the dodecahedral site will result in a change in force constant of the molecule. Even though the presence of $\mathrm{Ca}$ is negligible; the quantity of $\mathrm{Mg}$ is

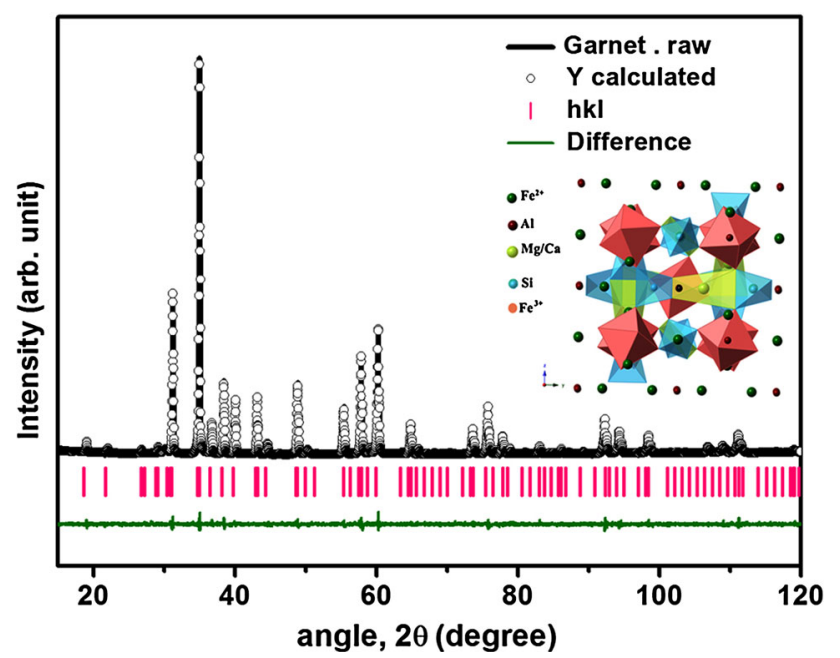

Fig. 1. The Rietveld refined XRD pattern of almandine-pyrope solid solution binary. significant to influence the molecular structure, which can be analyzed using molecular spectroscopy. The cations at the dodecahedral site $(\mathrm{Fe}$, $\mathrm{Mg}$, Ca etc.) are responsible for the bands below $400 \mathrm{~cm}^{-1}$ and the cations in the octahedral site $\left(\mathrm{Al}^{3+}, \mathrm{Fe}^{3+}\right.$ etc. $)$ result in the bands between 400 and $500 \mathrm{~cm}^{-1} .{ }^{24}$ The internal vibrations of the $\mathrm{SiO}_{4}$ tetrahedron are the major reasons for the bands corresponding to the middle infrared region. ${ }^{8}$ The low frequency bands below $400 \mathrm{~cm}^{-1}$ show two peaks instead of a single peak with intensities proportional to the amount of two cations in the dodecahedral site. ${ }^{7}$ The differences in ionic masses and force constants of $X$ site cations result in two mode behavior of bands in garnet solid solution binaries. ${ }^{25}$ Figure 3 shows the FTIR spectrum of the sample. The observed bands and their assignments are shown in Table III. The two strong bands and a weak shoulder around $800-1000 \mathrm{~cm}^{-1}$ can be assigned to $\mathrm{Si}-\mathrm{O}$ asymmetric stretching vibrations. These bands are independent of multiple cations that might present in the dodecahedral site. Another group of bands around $500-650 \mathrm{~cm}^{-1}$ are due to $\mathrm{Si}-\mathrm{O}$ asymmetric bending vibrations. The bands between adjacent $\mathrm{SiO}_{4}$ tetrahedrons and the

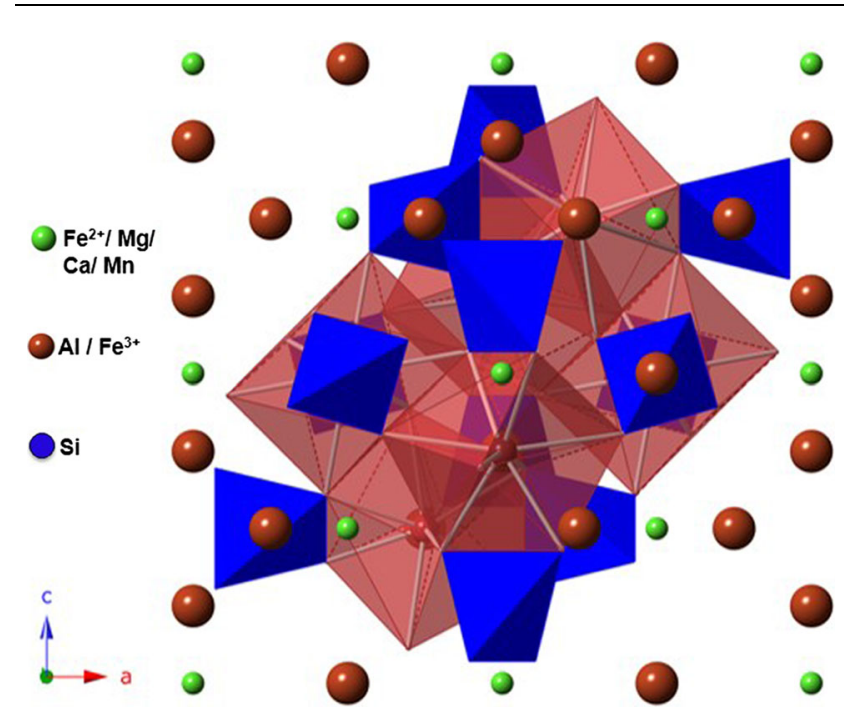

Fig. 2. Polyhedral representation of the crystal structure of $\mathrm{Al}_{70} \mathrm{Py}_{29}$.

\begin{tabular}{|c|c|c|c|c|c|}
\hline Elements & $\boldsymbol{x}$ & $y$ & $z$ & Occupancy & Displacement parameter $\left(\AA^{2}\right)$ \\
\hline $\mathrm{Fe}^{2+}$ & 0 & 0.25 & 0.125 & 0.67 & 1.345 \\
\hline $\mathrm{Mg}^{2+}$ & 0 & 0.25 & 0.125 & 0.31 & 0.955 \\
\hline $\mathrm{Ca}^{2+}$ & 0 & 0.25 & 0.125 & 0.007 & 0.586 \\
\hline $\mathrm{Mn}^{2+}$ & 0 & 0.25 & 0.125 & 0.004 & 0.586 \\
\hline $\mathrm{Al}^{3+}$ & 0 & 0 & 0 & 0.98 & 0.831 \\
\hline $\mathrm{Fe}^{3+}$ & 0 & 0 & 0 & 0.02 & 0.387 \\
\hline $\mathrm{Si}^{4+}$ & 0 & 0.25 & 0.375 & 0.98 & 0.283 \\
\hline $\mathrm{O}^{2-}$ & 0.035 & 0.053 & 0.652 & 1 & 0.301 \\
\hline
\end{tabular}

Table II. Crystallographic data for almandine pyrope solid solution 
cations present at different sites of garnets resulted in the appearance of bands in these two regions. ${ }^{8}$

The band in the $600-650 \mathrm{~cm}^{-1}$ region is absent for pyrope and this feature has been used to distinguish pyrope from other garnets. ${ }^{10}$ The FTIR spectrum of the mineral under study consists of this peak $\left(639 \mathrm{~cm}^{-1}\right)$ and is due to the presence of almandine in the garnet solid solution. Moreover, it is a single peak for pure almandine whereas the splitting of peak in the $600-650 \mathrm{~cm}^{-1}$ in the present IR spectrum indicates the multiple occupancy of cations in the dodecahedral site, and its intensity depends on the pyrope percentage. ${ }^{7,10}$ The study on the influence of $\mathrm{CaO}$ present in the almandine-pyrope solid solution shows that, if the amount of $\mathrm{CaO}$ present is below $2.20 \%$, then the peaks below $500 \mathrm{~cm}^{-1}$ are sharp; whereas for significant amounts of $\mathrm{CaO}$ the bands in these region becomes broad. ${ }^{10}$ McAloon et al. $^{26}$ reported that two mode behavior was observed for bands corresponding to the octahedral site due to the large difference in mass of ions occupying the octahedral site. Absence of peak splitting in the region $425-475 \mathrm{~cm}^{-1}$ is due to the negligible amount of $\mathrm{Fe}^{3+}$ in this site, which is also confirmed by the EPMA data. The peak positions of

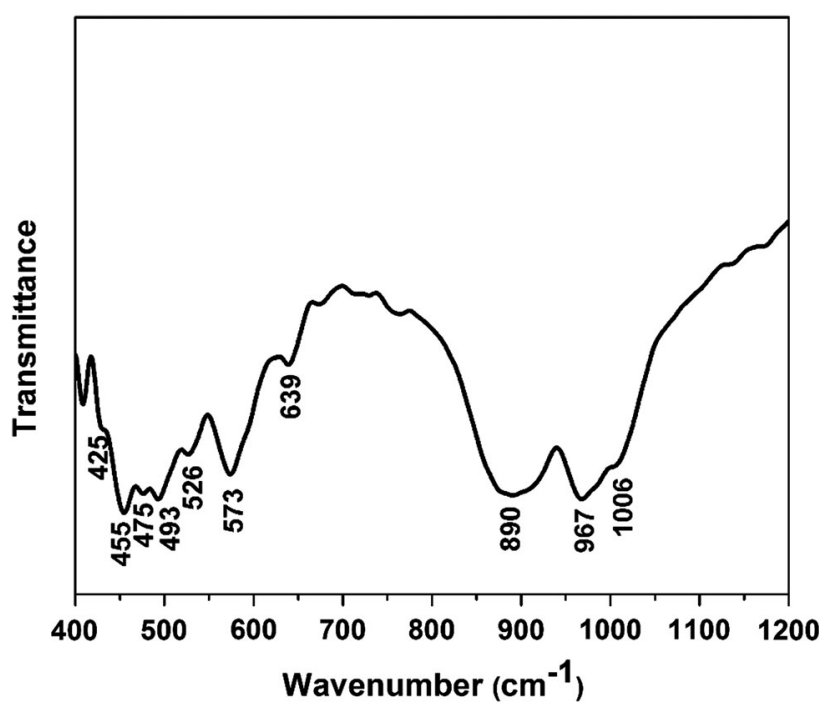

Fig. 3. FTIR spectra of the almandine-pyrope solid solution in mid IR region.

Table III. Wavenumbers and their corresponding band assignments in the mid IR region

\begin{tabular}{|c|c|}
\hline Wave number $\left(\mathrm{cm}^{-1}\right)$ & Band assignments \\
\hline $425-475 \mathrm{~cm}^{-1}$ & Translational mode of $\mathrm{Al}$ \\
\hline $493 \mathrm{~cm}^{-1}$ & Rotational mode of $\mathrm{SiO}_{4}$ \\
\hline $526-639 \mathrm{~cm}^{-1}\left(3 v_{4}\right)$ & $\mathrm{Si}-\mathrm{O}$ asymmetric bending \\
\hline $800-1100 \mathrm{~cm}^{-1}\left(3 v_{3}\right)$ & $\begin{array}{l}\text { Si-O asymmetric stretching } \\
\text { vibrations }\end{array}$ \\
\hline
\end{tabular}

garnets can be conspicuously influenced by the presence of more than $10 \mathrm{~mol} \%$ of an impurity (e.g., other garnet components in the pyrope-almandine solid-solution); whereas impurity contents below $10 \mathrm{~mol} . \%$ have negligible effect. ${ }^{3}$ In the present IR spectrum there is no significant peak shift from that of the pure garnet. This is because there is only less than 2 mol.\% of impurities in the almandine-pyrope solid solution, and the EPMA analysis confirmed this fact.

The unpolarised FT-Raman spectra of the mineral in the range $100-1000 \mathrm{~cm}^{-1}$ is shown in Fig. 4. The excitation wavelength is $1064 \mathrm{~nm}$, with a power of $10 \mathrm{~mW}$. Table IV shows the Raman active vibrational modes in the garnet structure. According to factor group analysis, for garnets there are 25 Raman active modes $\left(3 \mathrm{~A}_{1 \mathrm{~g}}+8 \mathrm{E}_{\mathrm{g}}+14 \mathrm{~F}_{2 \mathrm{~g}}\right)$. However, the present unpolarised spectra consist of only 18 peaks. $3 \mathrm{~A}_{1 \mathrm{~g}}$ modes, $10 \mathrm{~F}_{2 \mathrm{~g}}$ modes and $5 \mathrm{E}_{\mathrm{g}}$ modes were identified in the present Raman spectrum. According to Hofmeister et al. $^{7}$ and Moore et al. ${ }^{24}$ the polarized spectra of garnets at different angles showed all the 25 peaks. Here, most of the $\mathrm{E}_{\mathrm{g}}$ modes are overlapped by the $A_{1 g}$ and $F_{2 g}$ modes. ${ }^{7}$ The $A_{1 g}$ modes have the maximum intensity. The symmetric stretching and symmetric bending vibrations of $\mathrm{SiO}_{4}$ are IR inactive due to the absence of change in dipole moment of the molecular units during these vibrations. However, these vibrations are Raman active and can be found in the Raman spectrum. The bands at $916 \mathrm{~cm}^{-1}, 344 \mathrm{~cm}^{-1}$, $367 \mathrm{~cm}^{-1}$ and $554 \mathrm{~cm}^{-1}$ are the specific Raman bands of Almandine. ${ }^{3}$ The band at $139 \mathrm{~cm}^{-1}$ is due to the translational motion of $\mathrm{Mg}^{2+}$ while the bands at $156 \mathrm{~cm}^{-1}$ and $171 \mathrm{~cm}^{-1}$ belong to the translational motion of $\mathrm{Fe}^{2+}$. The band at $171 \mathrm{~cm}^{-1}$ is a single peak for pure almandine, but a peak splitting is observed in the present spectrum, which can be explained on the basis of two mode behavior. ${ }^{7}$ This

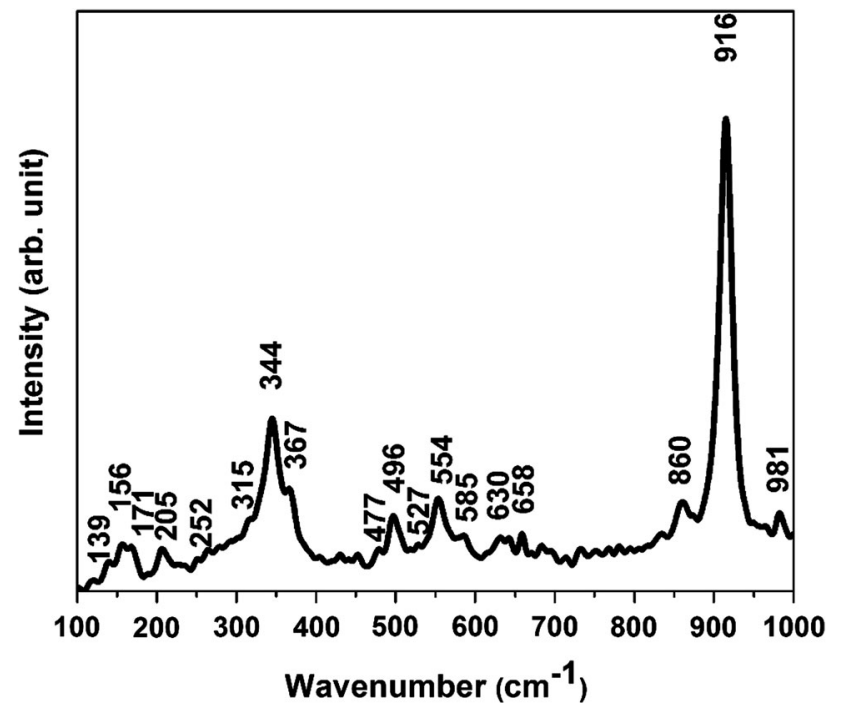

Fig. 4. Raman spectra of almandine-pyrope solid solution. 
Table IV. Wavenumbers and assignments of Raman bands

\begin{tabular}{lc}
\hline Wavenumber $\left(\mathbf{c m}^{-\mathbf{1}}\right)$ & Band assignments \\
\cline { 1 - 1 } $139\left(\mathrm{~F}_{2} \mathrm{~g}\right)$ & ${\text { Translational mode of } \mathrm{Mg}^{2+}}^{2+}$ \\
$156\left(\mathrm{~F}_{2 \mathrm{~g}}\right), 171\left(\mathrm{~F}_{2 \mathrm{~g}}\right), 252\left(\mathrm{E}_{\mathrm{g}}\right)$ & Translational mode of Fe $^{2+}$ \\
$205\left(\mathrm{E}_{\mathrm{g}}\right)$ & Translational mode of $\mathrm{SiO}_{4}$ \\
$315\left(\mathrm{~F}_{2 \mathrm{~g}}\right), 344\left(\mathrm{~A}_{1 \mathrm{~g}}\right), 367\left(\mathrm{E}_{\mathrm{g}}\right)$ & Rotational mode of SiO \\
$477,496,585\left(\mathrm{~F}_{2 \mathrm{~g}}\right) 527\left(\mathrm{E}_{\mathrm{g}}\right), 554\left(\mathrm{~A}_{1 \mathrm{~g}}\right)$ & Si-O symmetric bending vibrations, $\left(v_{2}\right)$ \\
$630\left(\mathrm{~F}_{2 \mathrm{~g}}\right), 658\left(\mathrm{~F}_{2 \mathrm{~g}}\right)$ & Si-O asymmetric bending vibrations, $\left(v_{4}\right)$ \\
$860\left(\mathrm{~F}_{2 \mathrm{~g}}\right), 916\left(\mathrm{~A}_{1 \mathrm{~g}}\right), 981\left(\mathrm{E}_{\mathrm{g}}\right)$ & Si-O symmetric stretching vibrations, $\left(v_{1}\right)$ \\
\hline
\end{tabular}

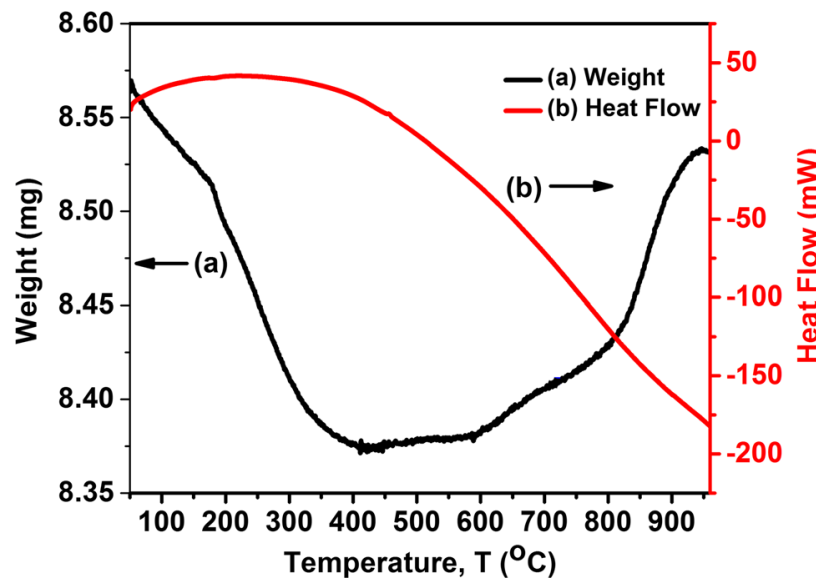

Fig. 5. TGA and DTA for almandine-pyrope solid solution in oxygen atmosphere.

might be due to the mass difference of $\mathrm{Fe}$ and $\mathrm{Mg}$ occupying the same dodecahedral site. Also, the presence of $\mathrm{Ca}$ will influence the intensity of this peak in a solid solution. ${ }^{3}$ The peak around $350 \mathrm{~cm}^{-1}$ can be used to distinguish pyrope from other garnets. Raman spectra of pyrope does not show a peak splitting in this region, while multiple peaks are observed for almandine around $350 \mathrm{~cm}^{-13}$. Hence, from Raman analysis, vibrational modes due to the presence of both almandine and pyrope were obtained. The data from FTIR and FT-Raman analysis also confirms that the obtained mineral comes under the almandine-pyrope solid solution series, and the multiple occupancy of cations in the dodecahedral and octahedral sites is confirmed.

\section{Thermal Stability of Almandine-Pyrope Solid Solution $\left(\mathbf{A l}_{\mathbf{7 0}} \mathbf{P y}_{\mathbf{2 9}}\right)$}

Figure 5 shows the Thermogravimetirc (TGA) and Differential Thermal curves (DTA) of the almandine-pyrope solid solution in the temperature range $0-960^{\circ} \mathrm{C}$. The thermal analysis was carried out in the presence of oxygen. A weight loss of nearly $1 \%$ is observed below $400^{\circ} \mathrm{C}$, which can be accounted for the evaporation of volatile impurities

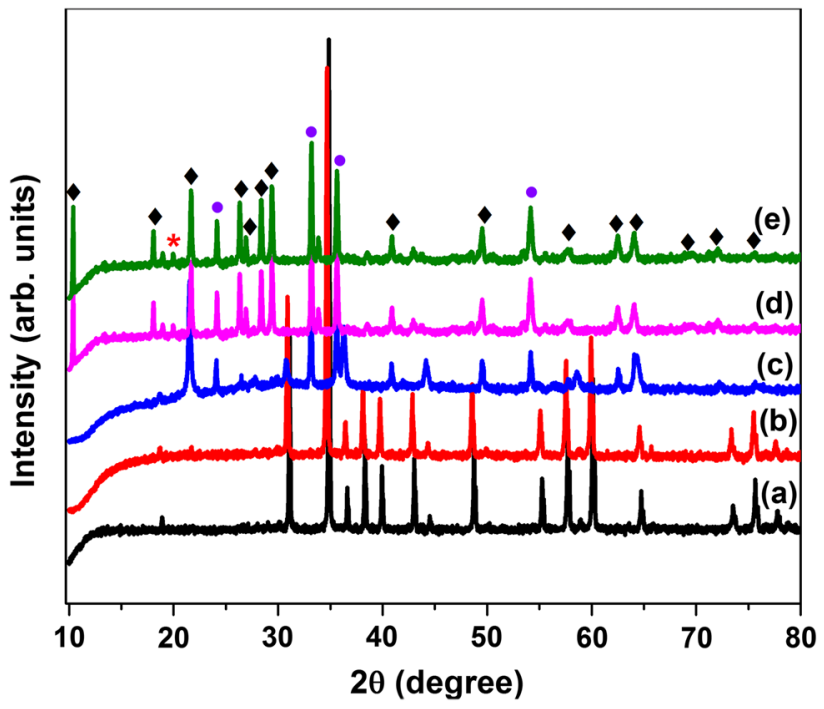

Fig. 6. XRD patterns for (a) G200, Garnet (b) G500, Garnet (c) G1000, Dorrite (d) G1200 \& (e) G1250 (*-cristobalite, -cordierite, -hematite).

like water. The mineral is observed to be stable below $600^{\circ} \mathrm{C}$. Above $600^{\circ} \mathrm{C}$ there is a weight gain, possibly due to the decomposition of the mineral. Absence of exothermic and endothermic peaks in the DTA curve agrees with the fact that there is no heat assisted phase change in the observed temperature range. The thermal analysis ensures the stability of the mineral below $600^{\circ} \mathrm{C}$.

Figure 6 shows the XRD patterns of samples heat treated at various temperatures. It shows the decomposition of samples at higher temperatures. $\mathrm{XRD}$ analysis proves that at $1000^{\circ} \mathrm{C}$, the almandinepyrope solid solution is completely decomposed to the mineral dorrite. The general formula of dorrite is $\mathrm{A}_{4}{ }^{2+} \mathrm{B}_{8}{ }^{3+} \mathrm{C}_{2}{ }^{4+} \mathrm{O}_{20}(\mathrm{~A}=\mathrm{Mg}, \mathrm{Ca}$, etc., $\mathrm{B}=\mathrm{Fe}, \mathrm{Al}$, etc. $\& \mathrm{C}=\mathrm{Si}$ ), which is a silicate mineral belonging to the aenigmatite group having triclinic structure. ${ }^{23}$ The XRD analysis of decomposed samples gives the space group as $\mathrm{P}-1(2)$ with lattice parameters $a=9.7784 \AA, b=10.3174 \AA, c=8.9075 \AA, \alpha=$ $93.63^{\circ}, \beta=112.36^{\circ}$ and $\gamma=65.05^{\circ}$. The mineral was decomposed due to the oxidation of almandine-pyrope solid solution at higher temperatures. 


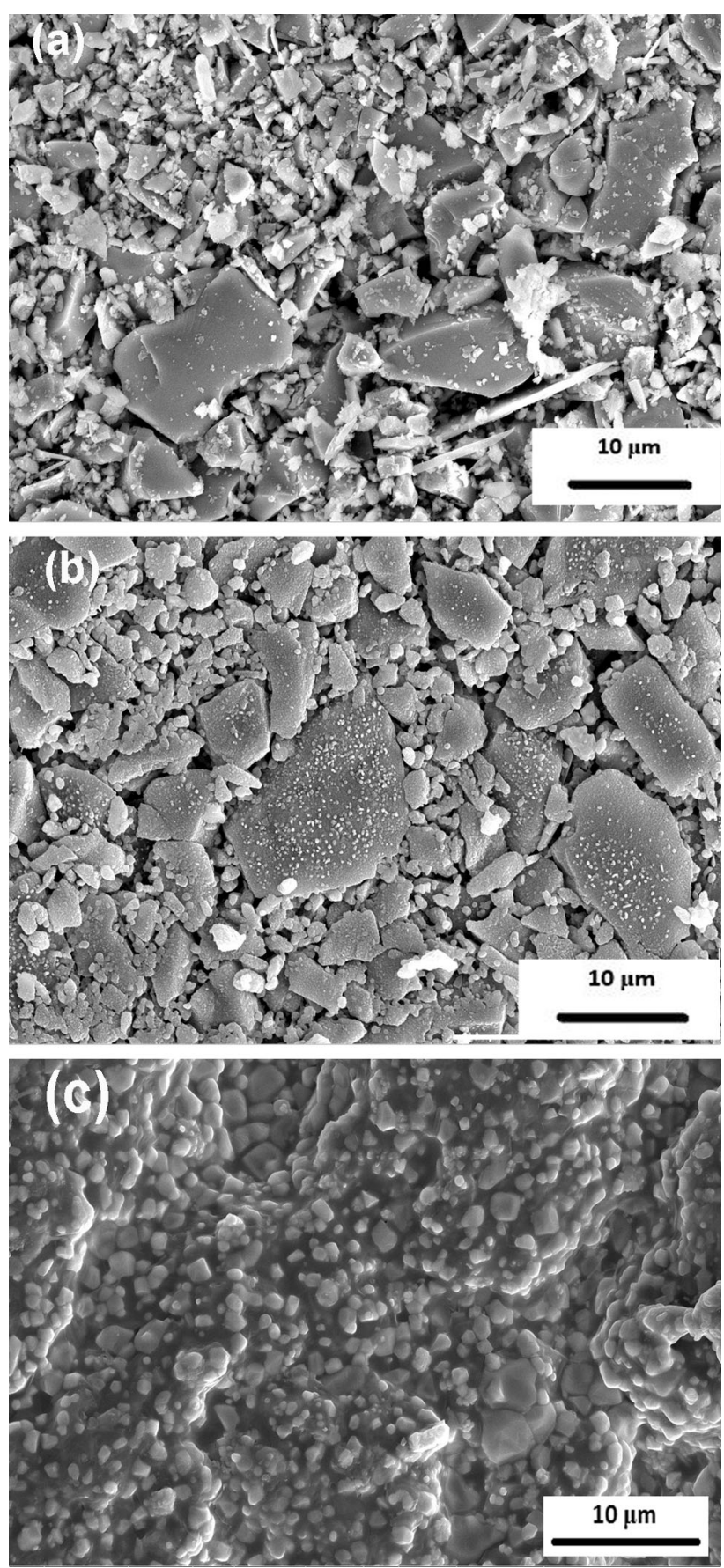

Fig. 7. SEM images of (a) G500 (b) G1000 (c) G1200.
After the decomposition, $\mathrm{Fe}^{2+}$ in $\mathrm{Al}_{70} \mathrm{Py}_{29}$ completely oxidized to $\mathrm{Fe}^{3+}$, which resulted in the observed weight gain of the mineral after $600^{\circ} \mathrm{C}$ in the TGA analysis. It is found that the mineral is undergoing further decompositions as the temperature is increased to $1200^{\circ} \mathrm{C}$. Dorrite decomposed to cordierite, hematite and cristobalite. The sample sintered at $1250^{\circ} \mathrm{C}$ shows no further decomposition, and the XRD pattern is similar to that of G1200.
Table V. EDAX data for G500 and G1000

\begin{tabular}{|c|c|c|}
\hline \multirow[b]{2}{*}{ Elements } & \multicolumn{2}{|c|}{ Atomic percentage $(\%)$} \\
\hline & G500 & G1000 \\
\hline $\mathrm{Fe}$ & 10.59 & 10.84 \\
\hline $\mathrm{Al}$ & 10.95 & 10.58 \\
\hline $\mathrm{Si}$ & 14.65 & 14.03 \\
\hline $\mathrm{Mg}$ & 6.4 & 5.92 \\
\hline $\mathrm{Ca}$ & 0.72 & 0.58 \\
\hline $\mathrm{Mn}$ & 0.13 & 0.41 \\
\hline $\mathrm{O}$ & 56.54 & 60.51 \\
\hline
\end{tabular}

\section{Microstructure}

Microstructures of samples heated at various temperatures were presented in Fig. 7. The SEM image Fig. $7 \mathrm{a}$ of the sample heat treated at $500^{\circ} \mathrm{C}$ (G500) shows randomly oriented grains. The shape of the grains are non-uniform with a large number of pores in between. The larger grains have a size of about $10 \mu \mathrm{m}$ while for the smaller grains the size ranges between $1 \mu \mathrm{m}$ and $4 \mu \mathrm{m}$. The microstructure Fig. $7 \mathrm{~b}$ of the sample heated at $1000^{\circ} \mathrm{C}$ (G1000) shows that there is an increase in grain size, which may be due to the decomposition of the mineral. The porosity of the dorrite sample is also high. Figure 7c shows the microstructure of Garnet sintered at $1200^{\circ} \mathrm{C}$ (G1200). The microstructure shows that the sample is well densified with a well interconnected network of grains. Also, the porosity has reduced considerably compared to G1000. Further densification is not possible since the mineral melted at a temperature of $1300^{\circ} \mathrm{C}$.

Table V shows the EDAX data for G500 and G1000. The atomic percentage of oxygen increases after phase transformation, while other elements ( $\mathrm{Fe}, \mathrm{Al}, \mathrm{Mg}, \mathrm{Si}, \mathrm{Ca}$ and $\mathrm{Mn}$ ) retain almost the same atomic percentage. The increase in atomic percentage of oxygen is in agreement with the information obtained from the XRD analysis of the decomposed sample. Also, the pointed SEM image and EDAX data (Fig. S4, S5) show that the constituent elements; $\mathrm{Fe}, \mathrm{Al}, \mathrm{Si}, \mathrm{Mg}, \mathrm{Mn}$ and $\mathrm{Ca}$ are found to be uniformly distributed in both the samples.

\section{Magnetic Properties of $\mathbf{A l}_{70} \mathbf{P y}_{29}$}

The physical properties of garnets such as refractive index, magnetic susceptibility, decomposition temperature, specific gravity, etc., have an approximate linear relation with their chemical composition. ${ }^{27}$ Measurement of such physical properties of garnets is a suitable method to identify their chemical composition. ${ }^{28,29}$ Usually ternary diagrams or triangular plots are used to predict the chemical compositions of solid solutions using the physical properties. ${ }^{29,30}$ Here, an alternative method is used to relate the magnetic properties and chemical composition of almandine-pyrope solid 
solution. Among the transition metal ions present in the garnets; $\mathrm{Fe}^{3+}, \mathrm{Mn}^{2+}\left(\mu_{\mathrm{eff}}=5.92 \mu_{\mathrm{B}}\right)$ and $\mathrm{Fe}^{2+}$ $\left(\mu_{\text {eff }}=4.9 \mu_{\mathrm{B}}\right)$ have the largest values of magnetic moment. ${ }^{31}$ Thus, magnetic measurements can indicate the quantity of these elements in the solid solutions. The experimental value of effective magnetic moment can be calculated from the Curie's constant, C, using the equation ${ }^{31}$ :

$$
\mu_{\text {eff }}=2.84 \sqrt{C} \mu_{\mathrm{B}} .
$$

The theoretical value of the effective magnetic moment can be found out from the equation ${ }^{32}$

$$
\mu_{\text {eff }}=\sqrt{x \mu_{\text {eff }}^{2}\left(\mathrm{Fe}^{2+}\right)+y \mu_{\text {eff }}^{2}\left(\mathrm{Fe}^{3+}\right)+z \mu_{\text {eff }}^{2}\left(\mathrm{Mn}^{2+}\right) \mu_{\mathrm{B}}},
$$

where $\mathrm{x}, \mathrm{y}$ and $\mathrm{z}$ are the number of $\mathrm{Fe}^{2+}, \mathrm{Fe}^{3+}$ and $\mathrm{Mn}^{2+}$ atoms per formula unit, respectively, and $\mu_{\mathrm{eff}}$ $(\mathrm{Fe} / \mathrm{Mn})=g \sqrt{s(s+1)} ; g=2\left(\right.$ for $\mathrm{Fe}^{2+}, s=2$ and for $\left.\mathrm{Fe}^{3+} \& \mathrm{Mn}^{2+}, s=5 / 2\right)$.

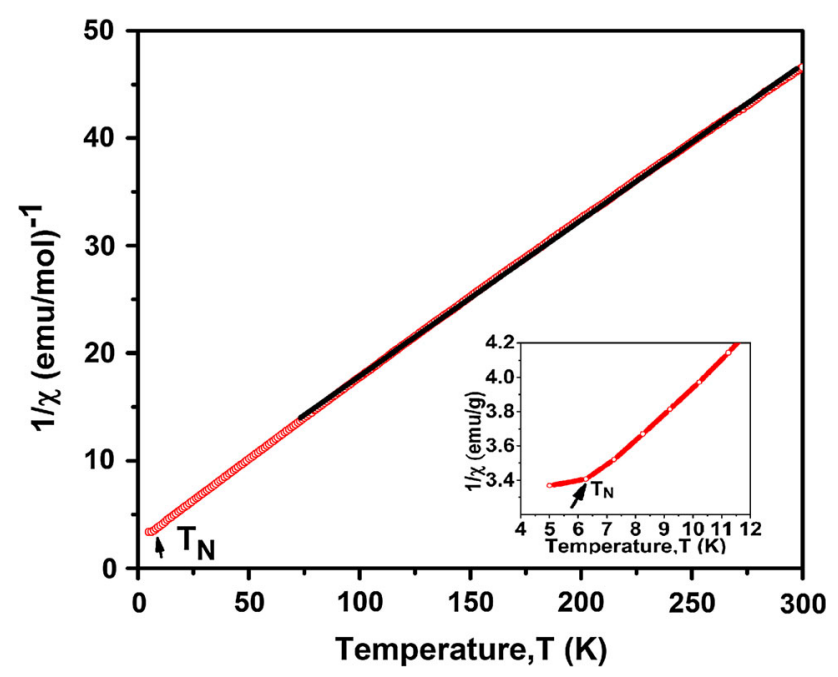

Fig. 8. Variation of inverse susceptibility of almandine-pyrope solid solution with temperature. (Inset shows the antiferromagnetic to paramagnetic transition of $\mathrm{Al}_{70} \mathrm{Py}_{29}$ ).
Garnets are usually antiferromagnetic in nature and their magnetic properties such as susceptibility, Neel temperature, magnetic moment, etc., varies with the quantity of magnetic ions present. ${ }^{6}$ As the $\mathrm{Fe}^{2+} / \mathrm{Fe}^{3+}$ ratio increases, the effective magnetic moment as well as the Neel temperature of the solid solution decreases. ${ }^{6}$

Figure 8 shows the temperature dependence of inverse susceptibility of the sample. The Weiss's constant is given by the $\mathrm{x}$-intercept, and it is found to be $\theta=(-23.32 \pm 0.21) \mathrm{K}$. The negative sign of Weiss' constant indicates that the dominant interactions present in almandine-pyrope solid-solution are antiferromagnetic, which is due to the disordered $\mathrm{Fe}^{2+}$ and $\mathrm{Mg}^{2+}$ ions. The mineral exhibits an antiferromagnetic to paramagnetic transition at the Neel temperature, $T_{\mathrm{N}}=6.2 \mathrm{~K}$. The paramagnetic susceptibility follows the Curie-Weiss law above the Neel temperature. Curie's constant is calculated as the inverse of the slope and it is deduced to be $C=(6.89 \pm 0.01) \mathrm{K}$. The experimental value of effective magnetic moment obtained is $\mu_{\text {eff }}=7.43$ $\mu_{\mathrm{B}}$. From the EPMA analysis, chemical composition of the almandine-pyrope solid solution is identified as $\left(\mathrm{Fe}_{1.72} \mathrm{Mg}_{0.8} \mathrm{Mn}_{0.01} \mathrm{Ca}_{0.02}\right)\left(\mathrm{Fe}_{0.04} \mathrm{Al}_{2.36}\right) \mathrm{Si}_{2.93} \mathrm{O}_{12}$; $x=1.72, y=0.04$ and $z=0.01$. The theoretical value of $\mu_{\text {eff }}$ based on above composition is about $6.56 \mu_{\mathrm{B}}$ which is nearly same as that obtained from susceptibility data. Hence, low temperature magnetic susceptibility data is also in agreement with the composition of magnetic ions obtained from EPMA analysis.

\section{Dielectric Properties of $\mathbf{A l}_{70} \mathbf{P y}_{29}$}

Microstructure of a material has significant influence on its dielectric properties. Porosity, grain size, grain boundaries, homogeneity of the grains, etc., are some of the factors that could determine permittivity $\left(\varepsilon_{\mathrm{r}}\right)$ and dielectric loss $(\tan \delta)$. Radio frequency dielectric measurements of the almandine-pyrope solid solution were carried out at $1 \mathrm{MHz}$. For dielectric measurements, $\mathrm{Al}_{70} \mathrm{Py}_{29}$ samples were heat treated at $500^{\circ} \mathrm{C}$ and $600^{\circ} \mathrm{C}$. Since the sintering temperature was low, density of the samples obtained was about $67 \%$. Although heating

Table VI. Radio frequency dielectric properties and bulk density of almandine-pyrope solid solution before

\begin{tabular}{|c|c|c|c|}
\hline Sample name & Dielectric constant ( $1 \mathrm{MHz}$ ) & $\tan \delta(1 \mathrm{MHz})$ & Bulk density $\left(\mathrm{g} / \mathrm{cm}^{3}\right)$ \\
\hline G500 & 6.0 & 0.036 & 2.6075 \\
\hline G600 & 7.9 & 0.033 & 2.6418 \\
\hline G700 & 7.4 & 0.022 & 2.4580 \\
\hline G900 & 9.1 & 0.008 & 2.4500 \\
\hline G1000 & 8.9 & 0.023 & 2.3025 \\
\hline G1100 & 8.8 & 0.021 & 2.2495 \\
\hline G1200 & 6.0 & 0.024 & 2.3300 \\
\hline G1250 & 16.5 & 0.047 & 2.5341 \\
\hline
\end{tabular}
and after decomposition 
at higher temperatures decompose the mineral, dielectric properties of decomposed samples were also studied for comparison.

The measured values of dielectric constant and loss tangent are tabulated in Table VI. Garnet mineral $\left(\mathrm{Al}_{70} \mathrm{Py}_{29}\right)$ possess low dielectric constant $\left(\varepsilon_{\mathrm{r}}\right)$, the values of which ranges from 6 to 7.4. The microstructural analysis shows that the sample is highly porous at these temperatures. As the porosity of the material increases, the dielectric constant decreases because of the low permittivity of air. The values of dielectric loss are reasonably good even without proper densification, which is about 0.03 . As the temperature is increased to $900^{\circ} \mathrm{C}$, the sample starts decomposing and for G1000 and G1100, the dielectric constant is increased to 8.9. This might be due to the larger dielectric constant of Dorrite mineral. As the sample is sintered at $1200^{\circ} \mathrm{C}$, the dielectric constant decreased to 6.0 . This might be due to decomposition of dorrite mineral into cordierite $\left(\varepsilon_{\mathrm{r}}\right.$ of $\left.4-5\right)$, cristobalite $\left(\varepsilon_{\mathrm{r}} \approx 4\right)$ and hematite $\left(\varepsilon_{\mathrm{r}} \approx 350\right)^{33,34}$ and the amount of hematite present in the decomposed sample is much less than that of cordierite. As the sintering temperature increased to $1250^{\circ} \mathrm{C}$, the bulk density increased from $2.33 \mathrm{~g} / \mathrm{cm}^{3}$ to $2.53 \mathrm{~g} / \mathrm{cm}^{3}$ and hence, there is an increase in dielectric constant. The dielectric properties of the garnet depend on sintering temperature and its decomposition. If the density of garnet mineral is improved without decomposition, better dielectric properties can be obtained. The densification of $\mathrm{Al}_{70} \mathrm{Py}_{29}$ can be improved by hot isostatic pressing and cold sintering, which will be done as a future work. Further, $\mathrm{Al}_{70} \mathrm{Py}_{29}$ can be used as a filler for fabricating ceramic polymer composites. Also, the present mineral is cheap and "green" as it contains $\mathrm{Fe}, \mathrm{Al}$ and $\mathrm{Si}$ elements only.

\section{CONCLUSIONS}

In this work, natural garnets in the almandinepyrope solid solution series, $\mathrm{Fe}_{3-\mathrm{x}} \mathrm{Mg}_{\mathrm{x}} \mathrm{Al}_{2} \mathrm{Si}_{3} \mathrm{O}_{12}$ were systematically studied in order to understand their feasibility for microwave applications. The EPMA analysis shows that the mineral is environmentally safe as it consists of only $\mathrm{Fe}^{2+}, \mathrm{Mg}^{2+}, \mathrm{Al}^{3+}$ and $\mathrm{Si}^{4+}$, with the trace elements $\mathrm{Ca}^{2+}, \mathrm{Mn}^{2+}$ and $\mathrm{Fe}^{3+}$. Rietveld refined XRD data is consistent with the occupancy of these ions at various crystallographic sites. An indication for the presence of calcium and magnesium in the dodecahedral site was obtained from FTIR analysis. Microstructural and thermal analysis ensures the stability of the mineral below $600^{\circ} \mathrm{C}$. The mineral decomposed to dorrite at $1000^{\circ} \mathrm{C}$, and it further decomposed to cordierite, hematite and cristobalite at higher temperatures. The chemical composition of $\mathrm{Al}_{70} \mathrm{Py}_{29}$ is correlated with its magnetic properties. Radio frequency dielectric measurements show favorable dielectric properties. The chemical composition and microstructure influenced the dielectric properties of the mineral at various temperatures. The structural and physical analysis shows the suitability of almandine-pyrope solid solution for microwave applications.

\section{ACKNOWLEDGEMENTS}

Sibi N. is grateful to Ministry of Minority Affairs, India and University Grants Commission, India for the award of Maulana Azad National Fellowship. Authors acknowledge Prof. Hiroshi Kageyama, University of Kyoto for magnetic measurement. Authors also acknowledge Dr. Sajeev Krishna, AFMM, IISC, Bangalore for the EPMA analysis of the sample. Authors acknowledge SERB project, YSS-000868/2014.

\section{ELECTRONIC SUPPLEMENTARY MATERIAL}

The online version of this article (doi:10.1007/ s11664-017-5801-5) contains supplementary material, which is available to authorized users.

\section{REFERENCES}

1. R. Mittal, S.L. Chaplot, and N. Choudhury, Phys. Rev. B 61, 3983 (2000).

2. R. Zboril, M. Mashlan, L. Machala, J. Walla, K. Barcova, and P. Martinec, Hyperfine Interact. 156-157, 403 (2004).

3. B.A. Kolesov and C.A. Geiger, Phys. Chem. Miner. 25, 142 (1998).

4. C.A. Geiger, Elements 9, 447 (2013).

5. E.F. Baxter, J.M. Caddick, and J.J. Ague, Elements 9, 415 (2013).

6. J.C.P. de Oliveira, M.I. da Costa, W.H. Schreiner, and A. Vasquez, J. Magn. Magn. Mater. 79, 1 (1989).

7. A.M. Hofmeister and A. Chopelas, Phys. Chem. Miner. 17, 503 (1991).

8. J. Dorschner and Astron Jena, Nachr. 293, 1 (1971).

9. A.M. Hofmeister, T.J. Fagan, K.M. Campbell, and R.B. Schaal, Am. Miner. 81, 418 (1996).

10. P. Tart and M. Deliens, Contr. Miner. Petrol 40, 25 (1973).

11. A.M. Ferrari, L. Valenzano, A. Meyer, R. Orlando, and R. Dovesi, J. Phys. Chem. A. 113, 11289 (2009).

12. T. Calligaro, S. Colinart, J.P. Poirot, and C. Sudres, Nucl. Instrum. Meth. A. 189, 320-327 (2002).

13. M. Shimpo, T. Tsunogae, and M. Santosh, Earth Planet. Sci. Lett. 242, 111 (2006).

14. G. Parthasarathy, R. Balaram, and V. Srinivasan, J. Asian Earth Sci. 17, 345 (1999).

15. M.H. Sabeen, N. Ramanujam, and A.C. Morton, Sediment. Geol. 152, 279 (2002).

16. J. Rajendran, P.K. Thampi, and G. Balasubramanian, Anal. Lett. 39, 2297 (2006)

17. M.T. Sebastian and H. Jantunen, Mater. Rev. 53, 57 (2008).

18. J. Varghese, D. Raghavan, P. Mohanan, and M.T. Sebastian, Phys. Chem. Chem. Phys. 17, 14943 (2015).

19. J. Varghese, Zircon Based Hard, Soft Microwave Substrates and Devices (Saarbrücken: LAP Lambert Academic Publishing, 2016).

20. R. Ratheesh and M.T. Sebastian, Microwave Materials and Applications, ed. M.T. Sebastian, R. Ubic, and H. Jantunen (New York: Wiley, 2017), p. 481.

21. P.L. Teh, M. Jaafar, H.M. Akil, K.N. Seetharamu, A.N.R. Wagiman, and K.S. Beh, Polym. Adv. Technol. 19, 308 (2008). 
22. R. Tessadri, Introduction to Minerological Sciences (Encyclopedia of Life Support Systems EOLSS, 2003), pp. 5-6.

23. M.A. Cosca, R.R. Rouse, and E.J. Essene, Am. Mineral. 73, 1440 (1988).

24. J. Koningstein and O.S. Mortensen, J. Mol. Spectrosc. 27, 343 (1968).

25. R.K. Moore, W.B. White, and T.V. Long, Am. Mineral. 56, 54 (1971).

26. C.A. Geiger, Eur. J. Mineral. 10, 407 (1998).

27. B.P. McAloon and A.M. Hofmeister, Am. Mineral. 80, 1145 (1995).

28. H. Winchell, Am. Mineral. 42, 595 (1958).
29. D.B. Hoover, B. Williams, C. Williams, and C. Mitchell, J. Gemm. 31, 91 (2008).

30. C.M. Stockton and D.V. Manson, Gems Gemol. 21, 205 (1985).

31. A.M. Omar, Elementary Solid State Physics (India: Dorling Kindersley, 2006), pp. 439-441.

32. G. Subodh, C. Tassel, N. Hayashi, Y. Goto, G. Bouilly, T. Yajima, Y. Kobayashi, and H. Kageyama, Eur. J. Inorg. Chem. 15, 2576 (2014).

33. B. Tang, Y.W. Fang, S.R. Zhang, H.Y. Ning, and C.Y. Jing, Indian J. Eng. Mater. S. 18, 221 (2011).

34. S.M. Reda, Int. J. Nanosci. 1, 17 (2013). 